\title{
Fear and Panic of COVID-19
}

\author{
Seyed Hassan Saadat ${ }^{1,2}$, Morteza Izadi ${ }^{3}$, Nematollah Jonaidi Jafari ${ }^{4}$, Hassan Abolghasemi ${ }^{5}$, Saeedreza \\ Jamalimoghadamsiyahkali ${ }^{6}$, Ali Jamalian ${ }^{1}$, Saeid Fathi ${ }^{7}$, Behzad Einollahi' ${ }^{2}$, Amir Hosein Ghazale ${ }^{8}$, Ramezan \\ Jafari ${ }^{9}$, Mehdi Mesri ${ }^{10}$, Mehrdad Ebrahimi ${ }^{2}$, Mosa Asadi ${ }^{2}$, Alireza Ghadian ${ }^{2}$, Zohreh Rostami ${ }^{2}$, Eghlim \\ Nemati $^{2}$, Hassan Nikoueinejad ${ }^{2}$, Bentolhoda Beyram ${ }^{2}$, Seyed Mohammad Hossein Tabatabaei ${ }^{11}$, Sina \\ Imanizadeh ${ }^{8}$, Milad Nafari², Mohammad Javanbakht ${ }^{2 *}$
}

\author{
${ }^{1}$ Behavioral Science Research Center, Lifestyle Institute, Baqiyatallah University of Medical Sciences, Tehran, Iran and \\ Shahid Lavasani Hospital, Tehran, Iran \\ ${ }^{2}$ Nephrology and Urology Research Center, Baqiyatallah University of Medical Sciences, Tehran, Iran \\ ${ }^{3}$ Travel Medicine Center of Iran, Tehran, Iran \\ ${ }^{4}$ Health Research Center, Baqiyatallah University of Medical Sciences, Tehran, Iran \\ ${ }^{5}$ Department of Pediatrics, Baqiyatallah University of Medical Sciences, Tehran, Iran \\ ${ }^{6}$ Department of Infectious Diseases, Tehran University of Medical Sciences, Tehran, Iran \\ ${ }^{7}$ University of Tehran, Tehran, Iran \\ ${ }^{8}$ Student Research Committee, Baqiyatallah University of Medical Sciences, Tehran, Iran \\ ${ }^{9}$ Department of Radiology, Baqiyatallah University of Medical Sciences, Tehran, Iran \\ ${ }^{10}$ Quran and Hadith Research Center, Baqiyatallah University of Medical Sciences, Tehran, Iran \\ ${ }^{11}$ Department of Orthopedics, Isfahan University of Medical Sciences, Isfahan, Iran
}

Corresponding Author: Mohammad Javanbakht, MD, Nephrology and Urology Research Center, Baqiyatallah University of Medical Sciences, Tehran, Iran. Tel: +98-9365295037, Email: mhmjvbt81@gmail.com

Received June 26, 2020; Accepted July 7, 2020; Online Published July 14, 2020

Citation: Saadat SH, Izadi M, Jonaidi Jafari N, et al. Fear and panic of COVID-19. Int J Travel Med Glob Health. 2020;8(3):91-92. doi:10.34172/ ijtmgh.2020.15.

$\mathrm{T}$ The world seems to be embroiled in a full-fledged media war in which "fear" is highlighted rather than discussions about the coronavirus disease 2019 (COVID-19). Despite all the current data, little is known about the real figures of COVID-19, and ignorance breeds fear all over the world, particularly in Iran. While media images are rapidly circulating and COVID-19 has become propaganda in many regions due to coronavirus rumors, one fear is in the public mind about mortality rates reported elsewhere. ${ }^{1,2}$

In the face of emergencies, a more interdisciplinary and cross-sectorial approach is of great importance for curtailing COVID-19 outbreak, which would, in turn, lead to a minimization of the damage. Transparency in reports and actions is also very important. ${ }^{3}$

The concept of health communication is of great importance. Now, in addition to trying to send scientific exchanges by traditional venues (e.g., journals and conferences), it must be explained to the public what really happened or is happening in public language (jargon and insider language) instead of scientific terminology, providing opportunities for engaging public audiences without customization. In other words, it is important to get a real perspective of the disease, such as initial estimates of epidemiological parameters, risk of acquiring infection, human-to-human transmission, and epidemic forecasts by considering what the public is hearing and practicing health communication. To a non-specialist, most specific terms in scientific language are not clear. Therefore, mass media can be targeted by representatives using a science communication approach and problem-based learning sessions, where a synergistic collaboration of multiple disciplines can be considered under the terms of One Health by human and animal health agencies, national organizations' downstream sectors, and scientific societies to underpin public health awareness based on reliable information.

Efforts at communicating information about infectious diseases should consider media outreach and community meetings. Moreover, an increased shift in special media sources in many parts of the world, including Internet use (e.g., websites), social media (e.g., Facebook, LinkedIn, Instagram, etc.), and Internet contacts can be of great importance for community engagement strategies based on infectious disease communication; other sources of health information, such as text alerts, artistic brochure design, and apps, are also easy strategies in this regard. Of course, the credibility of a source

Copyright $($ C 2020 The Author(s). This is an open-access article distributed under the terms of the Creative Commons Attribution License (http:// creativecommons.org/licenses/by/4.0), which permits unrestricted use, distribution, and reproduction in any medium, provided the original work is properly cited. 
and the issue of trust are markedly encouraged by providing communication strategies.

There is always the fear of creating anxiety because of uncertainty about the status of infectious diseases, ${ }^{4}$ particularly COVID-19. The concept of beliefs by anthropologists has been defined as emic (i.e. insider views) as opposed to it (i.e. outer views). ${ }^{5}$ These concepts must be taken into account in providing health communication practice and other interventions, as a series of rumors can turn people's beliefs into a cause for fear and anxiety. For example, the outsider view is that COVID-19 was genetically classified to be close to SARS-related coronaviruses of horseshoe bats. ${ }^{6}$ Social media has fueled uncertainty in Iran, where the rumor has spread among the public population.

Therefore, the provision of reliable and trusted communication channels based on public perceptions and reactions are of great importance, where framing messages can be effectively helpful in increasing public knowledge. ${ }^{7}$

On the other hand, the COVID-19 epidemic has provoked discriminatory behavior against individuals who are thought to have been exposed to the virus. This pandemic revealed that just thinking about oneself cannot be effective in protecting from disease, because it is affected by the health of the whole society and requires cooperative spirit, cooperation in dealing; irresponsible behaviors can endanger family, society, country, and the world.

Therefore, at the anthropological level, a series of filters (conceptual differences, cultural meanings, linguistic patterns, generations, and socioeconomic conditions) should also be taken into consideration for health communication to understand what the public is hearing about infectious diseases (e.g., COVID-19). For example, infectious disease communication may interfere with local customs, barriers, and constraints $^{8}$ (e.g., local behavior patterns, literacy and economic status, etc.), because they are associated with access to various information sources. ${ }^{5}$ Understanding what the public population is hearing in the light of cultural variations, feasibility of behaviors and other aforementioned issues are needed to be considered for health communication actions in terms of infectious disease outbreak, particularly COVID-19.

\section{Conclusion}

Experts and the public alike need to do our duty to avoid being part of the problem or a super-spreader of false news or rumors about COVID-19. The importance of infection disease communication can be highlighted in the light of reputable sources by providing reliable and trusted communication channels (e.g., the advice of public health experts). Therefore, what the public is hearing about infectious diseases (e.g., COVID-19) needs to be taken into consideration by scientists for effective health communication. Facilitating the free flow of data surrounding the COVID-19 outbreak (free-to-access resource) through credible data from journals can be helpful in translating this information to people's languages.

\section{Authors' Contributions}

All authors contributed equally to this study.

\section{Conflict of Interest Disclosures}

Morteza Izadi serves as a editor in chief of International Journal of Travel Medicine and Global Health. Other authors declare that they have no conflicts of interest.

\section{Ethical Approval}

Not applicable.

\section{Funding/Support}

None.

\section{References}

1. Murray S. The Fear of the Coronavirus, and the Reality of the Flu. https://www.mdmag.com/medical-news/the-fear-of-the-coronavirus-and-the-reality-of-the-flu. Published 2020.

2. Victor D. Panic and Criticism Spread on Chinese Social Media Over Coronavirus. The New York Times. January 24, 2020. https:// www.nytimes.com/2020/01/24/world/asia/china-social-mediacoronavirus.html.

3. Communication, collaboration and cooperation can stop the 2019 coronavirus. Nat Med. 2020;26(2):151. doi:10.1038/s41591-0200775-x.

4. Piper K. Don't Scold People for Worrying about the Coronavirus. Vox. February 6, 2020. https://www.vox.com/futureperfect/2020/2/6/21121303/coronavirus-wuhan-panic-pandemicoutbreak.

5. Scrimshaw SC. Science, health, and cultural literacy in a rapidly changing communications landscape. Proc Natl Acad Sci U S A. 2019;116(16):7650-7655. doi:10.1073/pnas.1807218116.

6. Lu R, Zhao X, Li J, et al. Genomic characterisation and epidemiology of 2019 novel coronavirus: implications for virus origins and receptor binding. Lancet. 2020;395(10224):565-574. doi:10.1016/s0140-6736(20)30251-8.

7. Scheufele DA. Communicating science in social settings. Proc Natl Acad Sci U S A. 2013;110 Suppl 3(Suppl 3):14040-14047. doi:10.1073/pnas.1213275110.

8. Ogawa VA, Shah CM, Alper J National Academies of Sciences, Engineering, and Medicine. Building Communication Capacity to Counter Infectious Disease Threats: Proceedings of a Workshop. Washington, DC: The National Academies Press; 2017. 